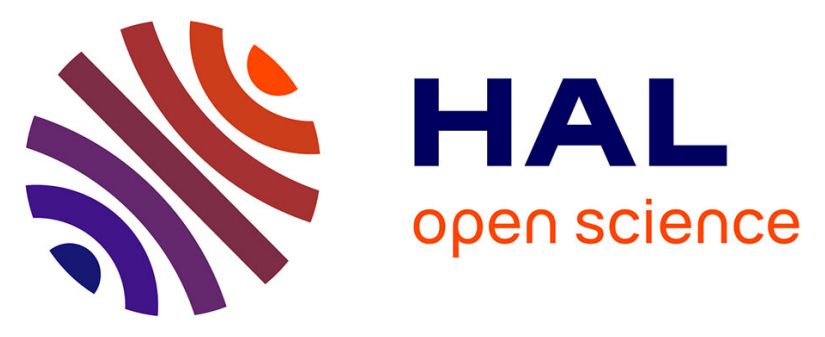

\title{
Simultaneous determination of aromatic and chlorinated compounds in urine of exposed workers by dynamic headspace and gas chromatography coupled to mass spectrometry (dHS-GC-MS)
}

\author{
Amandine Erb, Philippe Marsan, Manuella Burgart, Aurélie Remy,
} Anne-Marie Lambert-Xolin, Fanny Jeandel, Ogier Hanser, Alain Robert

\section{To cite this version:}

Amandine Erb, Philippe Marsan, Manuella Burgart, Aurélie Remy, Anne-Marie Lambert-Xolin, et al.. Simultaneous determination of aromatic and chlorinated compounds in urine of exposed workers by dynamic headspace and gas chromatography coupled to mass spectrometry (dHS-GC-MS). Journal of Chromatography B - Analytical Technologies in the Biomedical and Life Sciences, 2019, 1125, pp.121724 -. 10.1016/j.jchromb.2019.121724 . hal-03487319

\author{
HAL Id: hal-03487319 \\ https://hal.science/hal-03487319
}

Submitted on 20 Dec 2021

HAL is a multi-disciplinary open access archive for the deposit and dissemination of scientific research documents, whether they are published or not. The documents may come from teaching and research institutions in France or abroad, or from public or private research centers.
L'archive ouverte pluridisciplinaire HAL, est destinée au dépôt et à la diffusion de documents scientifiques de niveau recherche, publiés ou non, émanant des établissements d'enseignement et de recherche français ou étrangers, des laboratoires publics ou privés.

\section{(ㄷ)(1) $\$$}

Distributed under a Creative Commons Attribution - NonCommerciall 4.0 International 
Simultaneous determination of aromatic and chlorinated compounds in urine of exposed workers by dynamic headspace and gas chromatography coupled to mass spectrometry (dHS-GC-MS)

Amandine Erb*, Philippe Marsan, Manuella Burgart, Aurélie Remy, Anne-Marie Lambert-Xolin, Fanny Jeandel, Ogier Hanser, Alain Robert

INRS, Department Toxicology and Biomonitoring, Laboratory of Biomonitoring 1 rue du Morvan CS 60027, 54519 Vandœuvre Cedex, France

*: corresponding author, amandine.erb@inrs.fr, +33(0) 383508511

\section{ABSTRACT}

Mixed exposure to chemical products is a topical issue for occupational health and often includes exposure to volatile organic compounds (VOCs). As very few methods are available for evaluating these mixed exposures, the aim of this work was to develop a simple biomonitoring method to assess simultaneous occupational exposures to chlorinated and aromatic VOCs by analyzing the unmetabolized fraction of the VOCs in the urine of workers.

Volatile organic compounds were analyzed using dynamic headspace gas chromatography coupled to mass spectrometry (dHS-GC-MS), and 11 unmetabolized urinary VOCs were measured into headspace phase, without any time-consuming pretreatment. Simultaneously, a standardized collection protocol was designed to avoid VOC losses or the contamination of urinary samples. The calibration samples were real urines, spiked with known amounts of the VOC mixtures studied. Test investigations were performed on potentially exposed workers in three factories in order to assess the effectiveness of both the collection protocol and analytical method.

A satisfactory level of sensitivity was achieved, with limits of quantification (LOQ) between 10 and $15 \mathrm{ng} / \mathrm{L}$ obtained for all VOCs (except for styrene at $50 \mathrm{ng} / \mathrm{L}$ ). Calibration curves were linear in the $0-20 \mu \mathrm{g} / \mathrm{L}$ range tested, with $\mathrm{R}^{2}$ correlation coefficients of 0.991 to 0.998 . At the lowest concentration tested $(0.08 \mu \mathrm{g} / \mathrm{L})$, withinday precision varied from 2.1 to $5.5 \%$ and between-day precision ranged from 2.7 to $8.5 \%$.

Sample stability at $-20^{\circ} \mathrm{C}$ required that urinary samples be analyzed within 3 months. Even though the urinary concentrations of VOCs used in the plants were mostly quite low, significant differences between post-shift and pre-shift were observed.

In conclusion, a fast, sensitive, specific and easy-to-use method has been developed for extracting VOCs from human urine using dHS-GC-MS. The method described has proven to be reliable for assessing current occupational exposure to chlorinated and aromatic VOCs in France.

Keywords: BTEX, chlorinated compounds, urine, dynamic headspace, occupational exposure, biomonitoring

\section{Declarations of interest: None.}

Funding: This research did not receive any specific grant from funding agencies in the public, commercial, or not-for-profit sectors.

Informed consent: Informed consent was obtained from all individual participants included in the study. 


\section{Introduction}

Mixed exposure to chemical products is a topical issue for occupational health. Among hazardous chemicals, many volatile organic compounds (VOCs) widely used in industry are listed as CMR (carcinogenic, mutagenic or toxic to reproduction) or considered to be ototoxic compounds [1]. Even though they tend to be replaced by (other) less toxic substances, most are still in use. Aromatic compounds are in particular found in plants that produce and transform fuels and petrol products as well as in all chemical synthesis industries (e.g., polymers, resins, pesticides, varnish, and paints). Chlorinated compounds in particular have been substituted recently, but they are still used in laboratories as solvents as well as in the synthetics industry. Aromatic and chlorinated compounds can be found together in different industry, for example in the fields of organic synthesis or paints.

It is important that methods capable of evaluating mixed exposure are available in order to improve the health and safety of workers and to adapt collective and personal protection measures. Until now, however, very few studies have been carried out on simultaneous exposure to multiple VOCs with different chemical properties.

For the assessment of occupational exposure, atmospheric monitoring and biomonitoring are two tools available. Unlike atmospheric monitoring, biomonitoring includes all routes (inhalation, skin contact, and oral) and sources (occupational and environmental) of exposure to VOCs. It also takes into account the individual protection used as well as the intensity of physical activity, which can increase breathing rate and consequently the internal intake of VOCs [2]. In general, biomonitoring is performed on relevant metabolites, for example t,t-muconic or S-phenylmercapturic acid analysis for benzene, the latter being more appropriate for low occupational exposure $[3,4]$. However, other methods, based on analysis of the unmetabolized VOCs present in urine at trace levels, are also widely used. As VOC urinary concentrations result only from diffusion processes, they are not influenced by individual metabolism. Monitoring of the unchanged chemical in urine therefore allows inter-subject variability to be minimized. Urinary unmetabolized VOCs are therefore considered reliable indicators of exposure [5-9], and for benzene, they may even be better than S-phenylmercapturic acid at low urinary concentrations (below $1 \mu \mathrm{g} / \mathrm{L}$ of S-phenylmercapturic acid) [10,11].

Techniques available for analysis of the urinary unmetabolized VOCs that avoid any sample preparation are the headspace techniques, in static or dynamic mode or with solid-phase micro-extraction (SPME). In order to avoid interferences from the non-volatile compounds of the urinary matrix, only volatile compounds extracted from the headspace of a urine sample placed in an air-tight sealed vial are analyzed [12]. Thus, several compounds can be analyzed simultaneously. In contrast with liquid extractions, solvents are not required and the extraction is performed on-line so it is fast and easy to set up. As only volatile compounds are selected, cleaner chromatograms, with low noise levels and increased sensitivity, can be obtained In static mode, only a small amount of VOCs is extracted from the matrix and injected into the chromatographic system, while in dynamic mode, more or all of the VOCs present in urine are extracted and concentrated on an adsorbent trap. The dynamic mode changes the equilibrium towards the gas phase above the sample, transferring more VOCs into the headspace phase and thereby increasing the sensitivity of the method to allow analysis of trace compounds.

In the literature, different kinds of headspace techniques have been successfully applied for the monitoring of urinary VOCs such as benzene [13-15], toluene [2,16,17], mixtures of BTEX [18-22] and chlorinated compounds [23-26]. Nevertheless, to our knowledge, no method has previously been published that simultaneously analyzes aromatic and chlorinated compounds.

Our objective was to develop an original analytical method, using the dynamic headspace technique, to monitor benzene, toluene, ethylbenzene, o-, m-, p-xylenes (BTEX), styrene, dichloromethane, chloroform, trichloroethylene and tetrachloroethylene in a single analysis. The method was subsequently tested in different workplaces, using urinary samples from exposed workers.

\section{Material and method}

\subsection{Chemicals, standards and standard solutions}

A customized certified solution containing $100 \mathrm{mg} / \mathrm{L}$ of the 11 VOCs studied (benzene, toluene, ethylbenzene, $\mathrm{m}$-xylene, p-xylene, o-xylene, styrene, dichloromethane, chloroform, trichloroethylene and tetrachloroethylene) was purchased from Restek (France, Lisses). 
A stock solution containing $1 \mu \mathrm{g} / \mathrm{L}$ of each chemical was prepared in methanol (LC-MS grade, Merck, Germany, Darmstadt) by diluting the certified solution. An internal standard solution containing $1 \mathrm{mg} / \mathrm{L}$ of toluene-D8 $(100 \%, 99.96 \%$ D Sigma-Aldrich) was prepared in methanol. Both solutions were stored in amber-glass vials, at a temperature of $+4^{\circ} \mathrm{C}$, for at least 3 months, without significant VOC loss.

For the calibration and the method validation, "blank" urine samples from pooled urines, provided by nonoccupationally exposed, non-smoker adults, were used. These samples were collected in disposable polyethylene bottles and frozen at $-20{ }^{\circ} \mathrm{C}$ until analysis.

Just before analysis, calibration samples were prepared by dilution of the stock solution in blank urine, using Class A volumetric glass pipettes and $100 \mathrm{~mL}$ volumetric flasks equipped with PTFE caps. $20 \mathrm{~mL}$ headspace vials with silicone/PTFE screw caps, $1.5 \mathrm{~mm}$ thickness (Restek, France, Lisses), were compared to $20 \mathrm{~mL}$ headspace vials with silicone/PTFE crimp caps, $1.5 \mathrm{~mm}$ thickness (Perkin-Elmer, France, Villebon-sur-Yvette). Prior to analysis, $50 \mu \mathrm{L}$ of the internal standard solution was added to each urinary sample.

\subsection{Instruments and operations}

\subsubsection{Headspace apparatus}

A dynamic headspace sampler (TurboMatrix XL40, Trap Perkin Elmer, France, Villebon-sur-Yvette) was used to heat urine samples at $80{ }^{\circ} \mathrm{C}$ for $30 \mathrm{~min}$, directly in the headspace oven, and the gas phase was then collected on a trap (Air Monitoring Trap, Perkin Elmer). Afterwards, a 5-min-dry purge was performed to remove the trapped water. The VOCs concentrated on the trap were then subsequently desorbed by heating $\left(280{ }^{\circ} \mathrm{C}\right)$. Full details of the settings are reported in Table 1.

\subsubsection{Chromatography conditions}

A gas chromatograph (Perkin Elmer Clarus 680) equipped with a DB-5MS capillary column $(60 \mathrm{~m}, 0.25 \mathrm{~mm}$, $1 \mu \mathrm{m}$, Agilent, Santa Clara, USA) was used for the study, with helium as the carrier gas at constant pressure (25 psi). The column oven was programmed as follows: (i) $5 \mathrm{~min}$ at an initial temperature of $40{ }^{\circ} \mathrm{C}$; (ii) temperature increase to $85^{\circ} \mathrm{C}$ at a rate of $8{ }^{\circ} \mathrm{C} / \mathrm{min}$ then (iii) held at $85{ }^{\circ} \mathrm{C}$ for $20 \mathrm{~min}$; (iv) temperature increased to $250^{\circ} \mathrm{C} / \mathrm{min}$ at a rate of $45^{\circ} \mathrm{C} / \mathrm{min}$ and then (v) held at this final temperature for $5 \mathrm{~min}$. The total run time was $32 \mathrm{~min}$

\subsubsection{Mass spectrometer conditions}

Mass spectrometry (MS) was carried out using a Perkin Elmer Clarus SQ 8C operated in electron impact ionization EI+ mode $(70 \mathrm{eV})$, scanning ion mass fragments from 47 to $300 \mathrm{~m} / \mathrm{z}$ and with a source at $200^{\circ} \mathrm{C}$.

The mass spectrometric detection was conducted in two ways, Total Ion Current (TIC) and Single Ion Recording (SIR), resulting in increased signal-to-noise ratios. TIC was used to verify the profiles and SIR was used to quantify each compound: benzene $(\mathrm{m} / \mathrm{z} 78)$, toluene $(\mathrm{m} / \mathrm{z} 91)$, ethylbenzene $(\mathrm{m} / \mathrm{z} 104), \mathrm{m}-$, p-, o-xylenes $(\mathrm{m} / \mathrm{z}$ 91), dichloromethane $(\mathrm{m} / \mathrm{z} 84)$, chloroform $(\mathrm{m} / \mathrm{z} \mathrm{83)}$, trichloroethylene $(\mathrm{m} / \mathrm{z} \mathrm{130)}$, tetrachloroethylene $(\mathrm{m} / \mathrm{z}$ 166) and styrene $(\mathrm{m} / \mathrm{z}$ 104). Compounds were identified by comparing their mass spectra to those of the reference compounds of the commercial certified solution at corresponding retention times. Details of the MS settings and SIR settings are reported in Tables 2 and 3, respectively.

\subsection{Urinary sample volumes and storage optimization}

An Eppendorf Research Plus Single Channel Pipette with an adjustable volume of 1 to $10 \mathrm{~mL}$ was used to add a precise volume of urine sample to the headspace vial. Tests were performed with 2,5 and $10 \mathrm{~mL}$ of urine. Screw and crimp top vials were also tested. For the headspace analysis, it was particularly important to use vials and caps that ensure strong air-tightness, in order to avoid losses and achieve a maximum repeatability. Storage time tests were performed at room temperature, $+4{ }^{\circ} \mathrm{C}$ and $-20{ }^{\circ} \mathrm{C}$ on urine samples spiked with $1 \mu \mathrm{g} / \mathrm{L}$ and $10 \mu \mathrm{g} / \mathrm{L}$ for each VOC. 


\subsection{Method validation}

Method validation was performed to assess the following parameters: linearity, limits of quantification (LOD and LOQ) and method precision.

Matrix-matched calibration curves were used. For these, blank urine samples were spiked with the VOC stock solutions to generate final concentrations of $0.08,0.2,0.8,2,4,10$ and $20 \mu \mathrm{g} / \mathrm{L}$ for each compound. Five replicate analyses were performed at each concentration level. Linearity was tested at seven concentration levels within a concentration range of 0 to $20 \mu \mathrm{g} / \mathrm{L}$.

The limit of quantification was defined as ten times the signal-to-noise ratio close to the compound's retention time.

Precision (within-day and between-day) was evaluated by analyzing human urine spiked with each VOC at concentrations of $0.08,2$ and $20 \mu \mathrm{g} / \mathrm{L}$ in six replicates on three different days.

\section{$\underline{2.5 . \text { Field study }}$}

Investigations were carried out in three different industries that likely use aromatic and chlorinated VOCs: an oil refinery adopting special cleaning activities, for investigation of benzene, toluene, ethylbenzene and xylenes; a paint, varnish and resins manufacturer, for toluene, ethylbenzene, styrene, xylenes and chloroform; and an organic synthesis plant, for toluene and dichloromethane. About30 potentially exposed workers (smokers and non-smokers) at each site were included in the study.

Workers were given polypropylene $150 \mathrm{~mL}$ bottles in which to collect their urine. Afterwards, exactly $10 \mathrm{~mL}$ of the sample was transferred directly into $20 \mathrm{~mL}$ headspaces vials using a $10 \mathrm{~mL}$ manual single channel pipette equipped with disposable tips. Samples were frozen immediately after collection and remained frozen at $-20{ }^{\circ} \mathrm{C}$ until analysis.

Subjects were asked to provide pre- and post-shift samples of urine over 5 consecutive days, and were required to complete a form about their daily activities, any personal protection used, their smoking habits and any accidental skin exposure that may have occurred during their work shift. All samples were collected in duplicate.

\subsection{Statistical method}

Data were processed using Stata software. A logarithmic transformation was applied to the data. A mixed linear regression model was used to test the "time of collection of the urinary samples" (pre or post-shift) fixed effect or the "smoking" fixed effect, including a random effect termed "subject". This model was combined with a Tobit model in order to take into account concentrations below the LOQ. The statistical significance threshold was set at $5 \%$.

\section{Results and discussion}

\subsection{Dynamic Headspace analysis}

As unmetabolized VOCs are only present as traces in urine, a sensitive and selective method was needed to extract them from the urinary matrix. Dynamic headspace and gas chromatography coupled to mass spectrometry was chosen as it enables acceptable levels of quantification to be achieved for each VOC studied. The use of dynamic mode allowed the extraction rate to be increased and the unequivocal determination of all VOCs was facilitated through use of a mass spectrometer with a higher selectivity than a flame ionization detector (FID).

The extraction temperature of $80{ }^{\circ} \mathrm{C}$ was found to be best-adapted for extraction of the VOCs studied. For some compounds, the concentration extracted for 30 minutes was almost twice higher at $80^{\circ} \mathrm{C}$ than at $50^{\circ} \mathrm{C}$ (Figure 2) while temperatures above $80^{\circ} \mathrm{C}$ resulted in more water in the gas phase, which can reduce the life of the transfer line between the TurboMatrix XL40 and gas chromatograph, and decrease the efficiency of the VOC trap.

Urine blanks were used for the standard samples instead of water in order to remain as close as possible to the matrix of the studied samples. Tests comparing water and urine spiked with known amounts of VOCs showed that, for some compounds, a greater quantity was extracted from urine samples than from water samples. This 
difference was probably due to the high concentration of salts in urine, which may facilitate the transfer of VOCs from the liquid phase to the headspace phase.

Tests comparing crimped and screw caps showed no significant differences, even after freezing and thawing. Screw caps were chosen because screwing was easier than crimping in field studies, particularly because no crimping tool was required, and it was thus more convenient for field campaigns. An example of chromatogram obtained from spiked urine is shown in Figure 1.

\subsection{Optimization of urine sample storage}

Due to their volatility, VOCs are particularly susceptible to losses and it was therefore necessary to pay particular attention to the conservation of urinary samples.

The decision was made to freeze samples directly in the headspace vials for transport and storage. The glass material and the tightness of the cap allow losses or contamination to be avoided during transport of the urinary samples. Intermediate plastic bottles, as suggested by Ducos et al. [2], were also tried, but significant leaks occurred with the polypropylene bottles tested. For this study, we chose to use a protocol with as few steps as possible. The only requirement for collecting samples directly in the headspace vials was to have a $10 \mathrm{~mL}$ pipette with corresponding tips at the collection point. The procedure was found to be more reliable and precise than use of an intermediate container.

The time-stability study of urinary samples showed that VOCs losses could reach $10 \%$ per day at room temperature. In practice, the frozen urine samples never remained at room temperature for more than 24 hours between thawing and analysis. At $+4{ }^{\circ} \mathrm{C}$, after 7 days, losses reached about $10 \%$. After 90 days at $-20{ }^{\circ} \mathrm{C}$, a moderate loss of between 1 and $5 \%$ appeared, depending on the compound. The loss could reach more than $10 \%$ for most compounds after 120 days and it was therefore decided that storage at $-20{ }^{\circ} \mathrm{C}$ should not exceed 3 months.

A 30-minute heating of the sample at $80^{\circ} \mathrm{C}$ was enough to extract most of the VOCs present in urine. Increasing this heating time did not result in significant enhancement of the extraction. In contrast to the amounts of 1 or 2 $\mathrm{mL}$ usually used for headspace analysis, $10 \mathrm{~mL}$ of urine was found to be the quantity for which the extracted levels of the studied VOCs was the highest and the LOQs were thus lowest.

\subsection{Method validation}

For the calibration samples, Class A volumetric glass pipettes were used as these led to a better linearity than manual single channel pipettes. Toluene-d8 was used as an internal control standard to verify the effectiveness of the headspace extraction. Calibration curves at six concentration levels were linear in the range 0-20 $\mu \mathrm{g} / \mathrm{L}$, with $\mathrm{R}^{2}$ correlation coefficients ranging from 0.991 to 0.998 . The urinary limits of quantification were $10 \mathrm{ng} / \mathrm{L}$ for all compounds except for dichloromethane, p-xylene and styrene, whose LOQs were 15,15 and $50 \mathrm{ng} / \mathrm{L}$, respectively.

A previous study of exposure to toluene carried out in a rotogravure printing facility, conducted using a static headspace device and a gas chromatography coupled to a FID detector, showed a urinary toluene LOD of $500 \mathrm{ng} / \mathrm{L}$ [2]. For this compound, the LOD was thus 100 times lower at $5 \mathrm{ng} / \mathrm{L}$ using a dynamic headspace coupled with mass spectrometry in this study. Recent publications on urinary BTEX, using solid phase microextraction HS-SPME-GC-MS, reported LODs ranging from 36 to $86 \mathrm{ng} / \mathrm{L}$ [20], and LOQs from $6.7 \mathrm{ng} / \mathrm{L}$ to $64.6 \mathrm{ng} / \mathrm{L}$ [21] and from 3.2 to $25 \mathrm{ng} / \mathrm{L}$ [22]. Previously published data for chlorinated compounds [23] gave LODs of $5 \mathrm{ng} / \mathrm{L}$ for dichloromethane, trichloroethylene and tetrachloroethylene using HS-SPME technique, values that are in agreement with the present work. So, it is reasonable to claim that the method described in the current study will be sensitive enough to be applied to occupational sectors using aromatic and chlorinated VOCs.

The within-day and between-day precision of the method was tested at three different concentrations $(0.08,2$ and $20 \mu \mathrm{g} / \mathrm{L}, 6$ replicates). The results are summarized in Table 4.

At the lowest concentration of $0.08 \mu \mathrm{g} / \mathrm{L}$, the within-day precision ranged from 2.1 to $5.5 \%$ and the between-day precision from 2.7 to $8.5 \%$. 
With the optimized chromatographic conditions used, it was possible to separate and quantify o-, m- and pxylenes. Nevertheless, as their levels in urine were always statistically correlated, the measured excretions were summed and further labeled as "xylenes".

The laboratory took part in the German G-EQUAS external quality assessment scheme and the accuracy of analytical results for all BTEX was validated. Styrene, chloroform, dichloromethane, trichloroethylene and tetrachloroethylene were not available in G-EQUAS and subsequently were not tested.

\section{$\underline{\text { 3.4. Field application }}$}

The optimized method described above was applied to the analyses of the urine samples collected from subjects working in three different industries and potentially exposed to the VOCs studied. In the paint production plant, 29 exposed workers took part in the study, with 92 pre-shift and 74 post-shift urine samples collected. In the organic synthesis plant, 80 pre-shift and 80 post-shift urine samples were collected from 26 workers. In the oil refinery, 34 workers engaged in cleaning activities were recruited and 89 pre-shift and 88 post-shift urine samples were collected. The volunteers were mostly men, with women never exceeding $10 \%$ of the volunteers.

For BTEX, smoking habits have been considered as a confounding factor in the assessment of low occupational exposure [27-30]. Consequently, to test our method, only the results obtained from non-smokers are presented in Table 5.

All urinary samples were collected and analyzed in duplicate. In most cases, two duplicates gave similar results, differing by less than $20 \%$, and the urinary concentration of each VOC was therefore calculated using the mean of the two analyses performed. However, if the difference exceeded $20 \%$, only the highest urinary measured concentration was retained (based on the assumption that the less concentrated urinary sample was to the result of a loss of VOCs in one of the two vials).

The collection protocol (sampling, handling and storage) must be standardized to avoid possible losses or contamination at the sampling stage. These difficulties have already been described in the literature $[2,8,17,31]$. Sampling must be conducted in a room where the atmosphere has not been contaminated, for example in a separate building or in the infirmary, in order to avoid contamination of the sample by the polluted atmosphere. Similarly, the sampling must be carried out quickly, within 5 minutes after micturition, to avoid VOC losses or contamination. If these two conditions are respected, the robustness of the method is preserved.

The results of urinary analyses of non-smoker exposed workers in the three plants visited are summarized in Table 5.

To confirm occupational exposure to the VOCs studied, urinary pre-shift and post-shift excretions of nonsmoking exposed workers were compared. A statistically significant effect was a sign of occupational exposure. The results obtained from smokers are not presented here. In brief, when smokers were excluded, the difference between controls and BTEX-exposed workers was still more significant because interferences linked to the presence of occupational aromatic compounds in tobacco smoke were eliminated: for BTEX, a statistically significant difference between smokers and non-smokers was always observed for an equivalent level of exposure, as reported in previous publications [27-30].

With the exception of styrene, chloroform, dichloromethane and toluene, the VOCs studied were detected and measurable in all pre-shift urine samples collected in the different plants visited (Cf. Table 5) as these VOCs are part of the ubiquitous environmental pollution. For styrene, $90 \%$ of the results were below the $50 \mathrm{ng} / \mathrm{L} \mathrm{LOQ}$ in the pre-shift urinary samples. This is probably explained by a lower level of environmental contamination by this VOC, combined with its high LOQ (five times higher than for most of other VOCs).

In post-shift urinary samples, more quantifiable levels of VOCs were measured and these could be directly linked to the occupational exposure, with significantly higher medians for ethylbenzene and toluene recorded in the paints, varnish and resins plant, dichloromethane and toluene in the organic synthesis plant, and all BTEX except ethylbenzene in the oil refinery. For the other VOCs, the urinary levels could be attributed to environmental exposure. Examples of data obtained for a non-smoking control worker and for a non-smoking exposed worker from the refinery plant for a post-shift urinary sample are given respectively in Figures 3 and 4.

The organic synthesis plant was a particularly interesting example due to a simultaneous use of both aromatic and chlorinated compounds. Thus, the urinary concentrations of toluene and dichloromethane measured in the urinary samples were clearly linked to the occupational exposure, with very few values that were below the 
LOQ. The ability to quantify both aromatic and chlorinated compounds in the same urine sample was one of the aims of the method and was an important prerequisite for validating the efficiency of the method in field conditions.

For the urinary unmetabolized VOCs studied, only three urinary guidance values edited by American Conference of Governmental Industrial Hygienists (ACGIH) are available: toluene, styrene and dichloromethane, which have biological exposure indices (BEIs) of 30, 40 and $300 \mu \mathrm{g} / \mathrm{L}$ at the end of work shift, respectively [32]. For these three compounds, the urinary concentrations found during the three field campaigns never exceeded $10 \mu \mathrm{g} / \mathrm{L}$, so were far below the BEIs in each plant except in the organic synthesis plant, where toluene and dichloromethane had maximum urinary concentrations of around 14 and $23 \mu \mathrm{g} / \mathrm{L}$, respectively.

For unmetabolized urinary benzene and the other compounds studied, no biological limit values are available. For benzene, atmospheric exposure to the current French VME (mean exposure value) of 1 ppm permitted air concentration in the workplace, led to urinary excretions of between 1 and $10 \mu \mathrm{g} / \mathrm{L}$ as calculated using equations in the literature that link individual atmospheric benzene concentrations to workers post-shift urinary concentrations [13,33,34]. In 1996, the equation published by Ong and coworkers allowed a urinary benzene excretion of $2.4 \mu \mathrm{g} / \mathrm{L}$ to be determined, which corresponds to exposure to $1 \mathrm{ppm}$ of benzene over 8 hours. Another reference can be the MAK value corresponding to $1 \mathrm{ppm}$ of atmospheric benzene, which is a slightly higher, at $7.5 \mu \mathrm{g} / \mathrm{L}$ [35]. For this study, the choice was made to compare the workers urinary excretions to the value of $2.4 \mu \mathrm{g} / \mathrm{L}$ of urinary benzene, because a lower value is more protective for the workers. During cleaning activities in the oil refinery, $3.2 \%$ of the post-shift urinary samples from exposed non-smokers showed concentrations above this calculated $2.4 \mu \mathrm{g} / \mathrm{L}$ limit. For comparison, during standard work in this oil refinery, no concentration exceeded this calculated biological value (maximum $2.3 \mu \mathrm{g} / \mathrm{L}$ independent of the smoking habits of the workers; data not shown). In the oil refinery, it was interesting to note that the post-shift urinary levels of smokers with no or low occupational exposure were often lower than the pre-shift levels. We speculate that this loss may be attributed to a ban on smoking during the 8-hour work shift.

For toluene, Ducos et al. [2] showed that $50 \mathrm{ppm}$ of atmospheric toluene, which was the French VME before 2012 , led to a urinary concentration of $75.6 \mu \mathrm{g} / \mathrm{L}$, a concentration far higher than the maximum excretion level of $8.15 \mu \mathrm{g} / \mathrm{L}$ measured in the organic synthesis factory in the present work.

Our method has therefore proved sensitive enough for the assessment of current occupational exposure in the plants visited. Investigations should now be performed to verify the effectiveness of this new method for exposure to trichloroethylene and tetrachloroethylene.

\section{$\underline{\text { 4. Conclusions }}$}

The sampling and analysis method developed for the simultaneous analysis of 11 unmetabolized urinary VOCs was found to be reliable as long as simple rules are followed during sampling. The method is not timeconsuming as it does not require any clean-up procedure for urinary samples. The method is clearly very sensitive since it is capable of measuring urinary VOCs (with the exception of styrene) down to the 10 or $15 \mathrm{ng} / \mathrm{L}$ level. However, it is important to pay careful attention to the collection process and to the conservation of urinary samples. Sampling must be performed quickly, in a room without airborne VOCs, using headspace vials directly for transport and storage in order to avoid VOC losses before analysis. In addition, because the headspace technique does not allow second analysis of the sample (only "one-shot" analysis), at least two vials of each urine sample must be collected in order to avoid losing a result in cases of analytical issues or leakage problems for one of the analyses.

To our knowledge, this is the first time that a method evaluating mixed exposures to aromatic and chlorinated VOCs has been published. Low limits of quantification were obtained thanks to the high sensitivity of the dynamic headspace coupled with mass spectrometry technique. The procedure for the collection and conservation of urine samples in occupational settings that was adopted in this study proved to be efficient in a working environment. The method is well-suited for the biomonitoring of current occupational exposure to BTEX, styrene, chloroform and dichloromethane and is sensitive enough for measurement of environmental exposure. Tests remain to be conducted in workplaces that use trichloroethylene and tetrachloroethylene, in order to validate the method for these compounds as well. 
This investigation will continue with the assessment of current occupational exposures in various workplaces. It will hopefully prove to be a valuable tool for monitoring occupational exposure and helping occupational hygienist to keep exposure to VOCs as low as possible for the protection of workers' health.

\section{ACKNOWLEDGMENTS}

The authors would like to thank the management and the workers at the three plants investigated for their participation in this study.

\section{REFERENCES}

[1] INRS Base de données Biotox. http://www.inrs.fr/publications/bdd/biotox.html, 2018 (accessed 22 February 2019).

[2] P. Ducos, M. Berode, J.M. Francin, C. Arnoux, C. Lefevre, Biological monitoring of exposure to solvents using the chemical itself in urine: application to toluene, Int. Arch. Occup. Environ. Health 81 (2008) 273-284.

[3] R. Gaudin, P. Ducos, J.M. Francin, P. Marsan, A. Robert, T. Nicot, C. Lefevre, M. Lefebvre, Exposition au benzène chez les mécaniciens - Evaluation atmosphérique et surveillance biologique, Cahiers de Notes Documentaires 188 (2002) 26-36.

[4] M. Carrieri, G. Spatari, G. Tranfo, D. Sapienza, M.L. Scapatello, G.B. Bartolucci, M. Manno, Biological monitoring of low level exposure to benzene in an oil refinery: Effect of modulating factors, Toxicol. Lett. 298 (2018) 70-75.

[5] S. Ghittori, M.L. Fiorentino, L. Maestri, G. Cordioli, M. Imbriani, Urinary excretion of unmetabolized benzene as an indicator of benzene exposure, J. Toxicol. Environ. Health 38 (1993) 233-243.

[6] B. Janasik, M. Jakubowski, W. Wesolowski, M. Kucharska, Unmetabolized VOCs in urine as biomarkers of low level occupational exposure, Int. J. Occup. Med. Environ. Health 23 (2010) 21-26.

[7] S. Ghittori, M. Imbriani, G. Pezzagno, E. Capodaglio, The urinary concentration of solvents as a biological indicator of exposure: proposal for the biological equivalent exposure limit for nine solvents, Am. Ind. Hyg. Assoc. J. 48 (1987) 786-790.

[8] T. Kawai , K. Mizunuma , Y. Okada , S. Horiguchi , M. Ikeda, Toluene itself as the best urinary marker of toluene exposure, Int. Arch. Occup. Environ. Health 68 (1996) 289-297.

[9] M. Imbriani, S. Ghittori, Urinary excretion of unmetabolized benzene as an indicator of benzene exposure, Advances in Occupational Medicine and Rehabilitation 1 (1995) 177-188.

[10] S. Fustinoni, L. Campo, R. Mercadante, P. Manini, Methodological issues in the biological monitoring of urinary benzene and S-phenylmercapturic acid at low exposure levels, J. Chromatogr. B Analyt. Technol. Biomed. Life Sci. 878 (2010) 2534-2540.

[11] S. Fustinoni, M. Buratti, L. Campo, A. Colombi, D. Consonni, A.C. Pesatori, M. Bonzini, P. Farmer, S. Garte, F. Valerio, D.F. Merlo, P.A. Bertazzi, Urinary t,t-muconic acid, S-phenylmercapturic acid and benzene as biomarkers of low benzene exposure, Chem. Biol. Interact. 153-154 (2005) 253-256.

[12] A.C. Soria, M.J. Garcia-Sarrio, M.L. Sanz, Volatiles sampling by headspace techniques, Trends Anal. Chem. 71 (2015) 85-99.

[13] S. Waidyanatha, N. Rothman, S. Fustinoni, Urinary Benzene as a biomarker of exposure among occupationally exposed and unexposed subjects, Carcinogenesis 22 (2001) 279-286. 
[14] P. Hoet, E. De Smedt, M. Ferrari, M. Imbriani, L. Maestri, S. Negri, Evaluation of urinary biomarkers to exposure to benzene: correlation with blood benzene and influence of confounding factors, Int. Arch. Occup. Environ. Health 82 (2009) (8):985-995.

[15] M. Bader, T. Van Weyenbergh, E. Verwerfte, J. Van Puk, S. Lang, C. Oberlinner, Human biomonitoring after chemical incidents and during short-term maintenance work as a tool for exposure analysis and assessment, Toxicol. Lett. 231 (2014) 328-336.

[16] S. Fustinoni, R. Mercadante, L. Campo, L. Scibella, C. Valla, D. Consonni, V. Foà, Comparison between urinary o-cresol and toluene as biomarkers of toluene exposure, J. Occup. Environ. Hyg. 4 (2007) 1-9.

[17] S. Fustinoni, M. Buratti, R. Giampiccolo, G. Brambilla, V. Foà, A Colombi, Comparison between blood and urinary toluene as biomarkers of exposure to toluene, Int. Arch. Occup. Environ. Health 73 (2000) 389-396.

[18] T. Kramer Alkade, M. Do Carmo Ruaro Peralba, C. Alcaraz Zini, E. Bastos Caramao, Quantitative analysis of benzene, toluene, and xylenes in urine by means of headspace solid-phase microextraction, J. Chromatogr. A 1027 (2004) 37-40.

[19] S Fustinoni, R Giampiccolo, S Pulvirenti, M Buratti, A Colombi, Headspace solid-phase microextraction for the determination of benzene, toluene, ethylbenzene and xylenes in urine, J. Chromatogr. B 723 (1996) 105-115.

[20] B. Heibati, K.J. Godri Pollitt, J.Y. Charati, A. Ducatman, M. Shokrzadeh, A. Karimi, M. Mohammadyan, Biomonitoring-based exposure assessment of benzene, toluene, ethylbenzene and xylene among workers at petroleum distribution facilities, Ecotoxicol. Environ. Saf. 149 (2018) 18-25.

[21] A. Rafiee , J.M. Delgado-Saborit , P.D. Sly, H. Amiri , M. Hoseini, Lifestyle and occupational factors affecting exposure to BTEX in municipal solid waste composting facility workers, Science of the Total Environment 656 (2019) 540-554.

[22] X. Tsangari , X.D. Andrianou , A. Agapiou , P. Mochalski , KC Makris, Spatial characteristics of urinary BTEX concentrations in the general population, Chemosphere 173 (2017) 261-266.

[23] D. Poli, P. Manini, R. Andreoli, I. Franchini, A. Mutti, Determination of dichloromethane, trichloroethylene and perchloroethylene in urine samples by headspace solid phase microextraction gas chromatography - mass spectrometry, J. Chromatogr. B 820 (2005) 95-102.

[24] T. Sakai, Y. Morita, C. Wakui, Biological monitoring of workers exposed to dichloromethane, using headspace gas chromatography, J. Chromatogr. B 778 (2002) 245-250.

[25] K. Furuki, H. Ukai, S. Okamoto, S. Takada, T. Kawai, Y. Miyama, Monitoring of occupational exposure to tetrachloroethylene by analysis for unmetabolized tetrachloroethylene in blood and urine in comparison with urinalysis for trichloroacetic acid, Int. Arch. Occup. Environ. Health 73 (2000) 221-227.

[26] M. Imbriani, Q. Niu, S. Negri, S. Ghittori, Trichloroethylene in urine as biological exposure index, Indus. Health 39 (2001) 225-230. 
[27] S. Barbieri, F.S. Violante, L. Sabatini, F. Graziosi, S. Mattioli, Urinary biomarkers and low-level environmental benzene concentration: Assessing occupational and general exposure, Chemosphere 74 (2008) 64-69.

[28] G. De Palma, D. Poli, P. Manini, R. Andreoli, P. Mozzoni, P. Apostoli, A. Mutti , Biomarkers of exposure to aromatic hydrocarbons and methyl tert-butyl ether in petrol station workers, Biomarkers: biochemical indicators of exposure, response, and susceptibility to chemicals 17 (2012) 343-351.

[29] L. Campo, F. Rossella, R. Mercadante, S. Fustinoni, Exposure to BTEX and ethers in petrol station attendants and proposal of biological exposure equivalents for urinary benzene and MTBE, Annals of occupational hygiene 60 (2016) 318-333.

[30] P. Lovreglio, G. De Palma, A. Barbieri, R. Andreoli, I. Drago, L. Greco, E. Gallo, L. Diomede, P. Scaramuzzo, M.C. Ricossa, J. Fostinelli, P. Apostoli, L. Soleo, Biological monitoring of exposure to low concentrations of benzene in workers at a metallurgical coke production plant: new insights into Sphenylmercapturic acid and urinary benzene, Biomarkers 23(2018) 70-77.

[31] M. Ikeda, Solvents in urine as exposure markers, Toxicol. Lett. 108 (1999) 99-106.

[32] ACGIH, TLVs ${ }^{\circledR}$ and BEIs ${ }^{\circledR}$. Based on the documentation of the threshold limit values for chemical substances and physical agents and biological exposure indices. American Conference of Governmental Industrial Hygienists, Cincinnati, Ohio, 2018.

[33] C.N. Ong, P.W. Kok, H.Y. Ong, C.Y. Shi, B.L. Lee, W.H. Phoon, K.T. Tan, Biomarkers of exposure to low concentrations of benzene: a field assessment, Occup. Environ. Med. 53 (1996) 328-333.

[34] S.M. Hays, D.W. Pyatt, C.R. Kirman, L.L. Aylward, Biomonitoring Equivalents for benzene, Regulatory Toxicology and Pharmacology 62 (2012) 62-73.

[35] Permanent Senate Commission for the Investigation of Health Hazards of Chemical Compounds in the Work Area. Report 53. List of MAK and BAT values 2017, 2017, https://onlinelibrary.wiley.com/doi/pdf/10.1002/9783527812127.oth (accessed 10 July 2019).

Fig 1: TIC Chromatogram generated from dHS-GC-MS analysis of a blank urine sample spiked with $2 \mu \mathrm{g} / \mathrm{L}$ of each VOC (1: dichloromethane; 2: chloroform; 3: benzene; 4: trichloroethylene; 5: toluene-D8; 6: toluene; 7: tetrachloroethylene; 8: ethylbenzene; 9: m-xylene; 10: p-xylene; 11: styrene; 12: o-xylene).

Fig 2: Extraction of the VOCs at temperatures varying from $50^{\circ} \mathrm{C}$ to $80^{\circ} \mathrm{C}$ for 30 minutes. To simplify the graph, the value $100 \%$ was given to the area obtained for each compound at $80^{\circ} \mathrm{C}$.

Fig 3: TIC chromatogram and the corresponding SIR signals obtained from a post-shift urinary sample, from a control worker, non-smoker. "ND”: concentration below LOQ. The quantified compounds are labeled with “*”.

Fig 4: TIC chromatogram and the corresponding SIR signals obtained from a post-shift urinary sample, from an exposed worker, non-smoker. "ND”: concentration below LOQ. The quantified compounds are labeled with “*”. 


\section{Intensity}

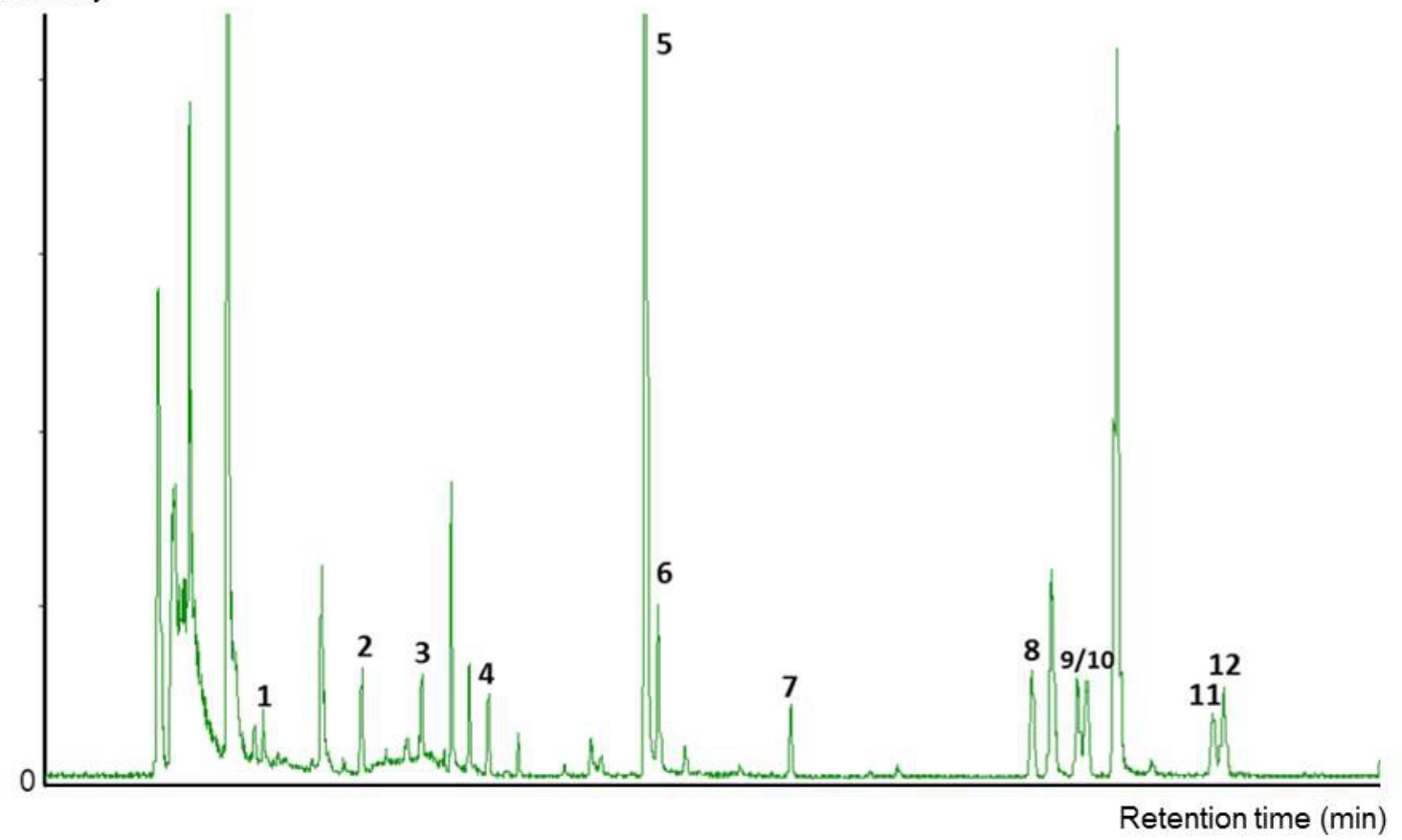




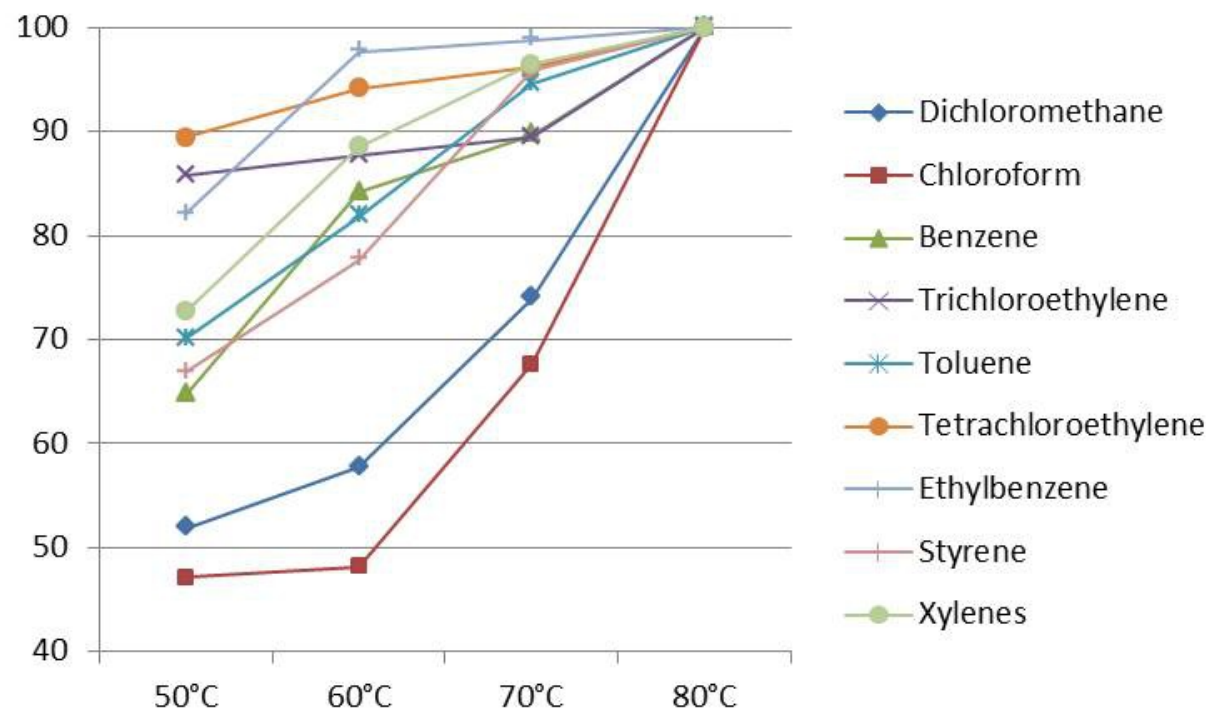



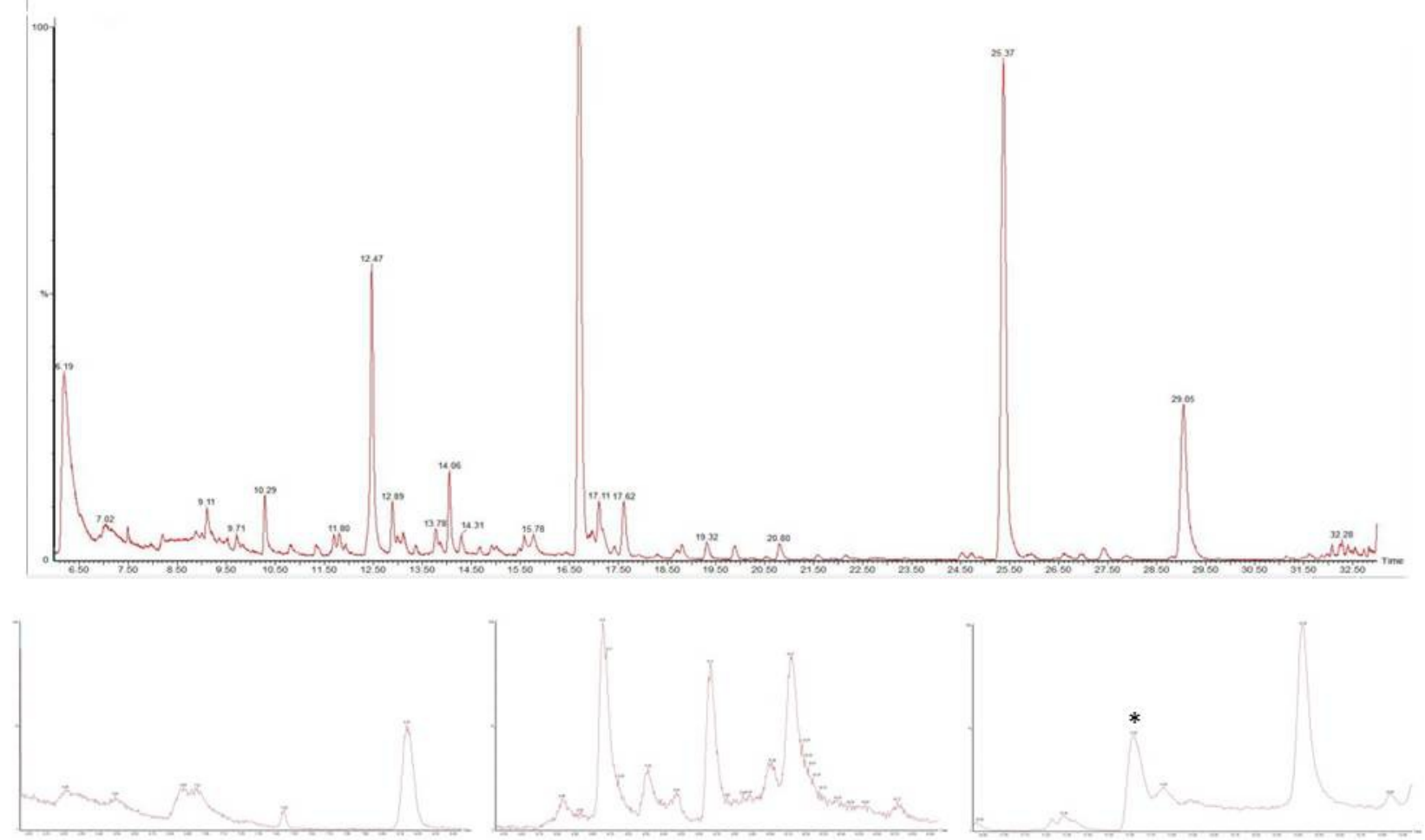

SIR1 : dichloromethane (ND)

SIR2 chloroform (ND)

SIR3 : benzene $\left(^{*}\right)$
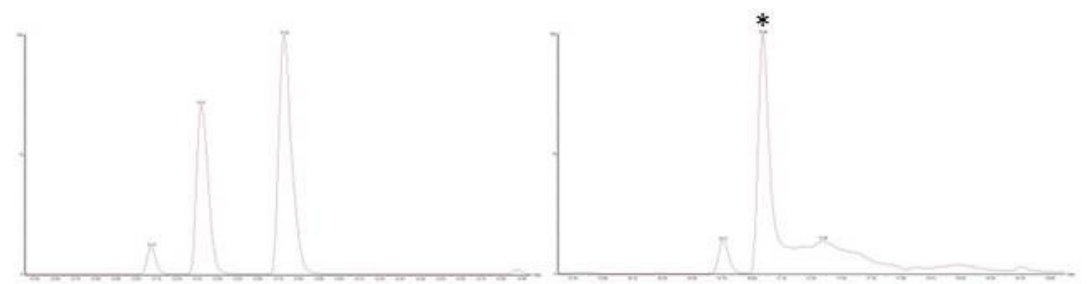

SIR4 : trichloroethylene (ND)

SIR6 : toluene $\left(^{*}\right)$
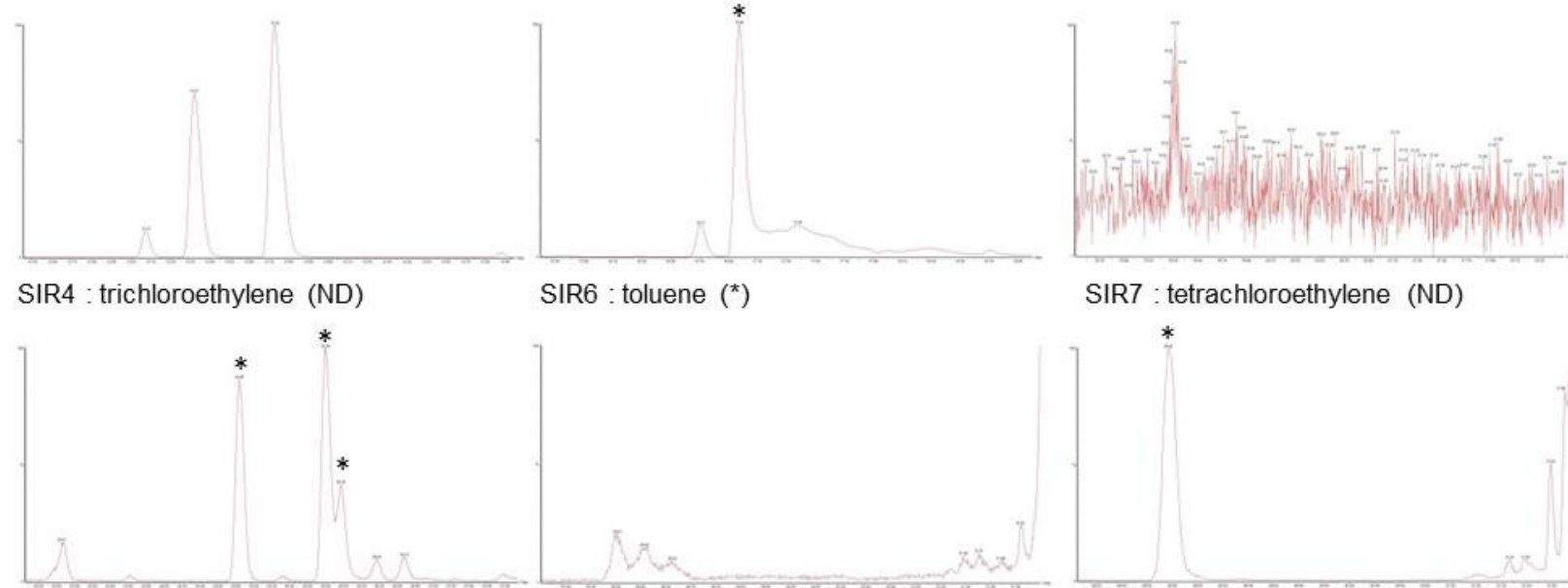

SIR7 : tetrachloroethylene (ND)

SIR8 : ethylbenzene, $\mathrm{m}$ - and p-xylenes $\left(^{*}\right)$ SIR9: styrene (ND)

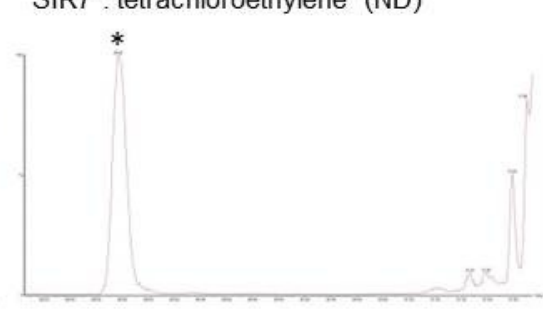

SIR10: o-xylene $\left({ }^{*}\right)$ 
Table 1: Instrumental Headspace settings

\begin{tabular}{|l|c|c|}
\cline { 2 - 3 } \multicolumn{1}{c|}{} & Instrument parameters & Settings \\
\hline \multirow{4}{*}{ Temperatures } & Needle & $140^{\circ} \mathrm{C}$ \\
\cline { 2 - 3 } & Trap & $40^{\circ} \mathrm{C}$ \\
\cline { 2 - 3 } & Trap desorption & $280^{\circ} \mathrm{C}$ \\
\cline { 2 - 3 } & Transfer line & $150^{\circ} \mathrm{C}$ \\
\cline { 2 - 3 } & Vial heating & $80{ }^{\circ} \mathrm{C}$ \\
\hline Times/durations & Number of cycles & 2 \\
\cline { 2 - 3 } & Pressurization & $1.0 \mathrm{~min}$ \\
\cline { 2 - 3 } & Decay time & $2.0 \mathrm{~min}$ \\
\cline { 2 - 3 } & Dry purge & $5.0 \mathrm{~min}$ \\
\cline { 2 - 3 } & Trap heating & $13.0 \mathrm{~min}$ \\
\cline { 2 - 3 } & Desorption & $30.1 \mathrm{~min}$ \\
\cline { 2 - 3 } & Vial heating & $30.0 \mathrm{~min}$ \\
\hline Pressures & Column (driven by HS) & $25.0 \mathrm{psi}(\mathrm{constant})$ \\
\cline { 2 - 3 } & Vials & $30.0 \mathrm{psi}$ \\
\cline { 2 - 3 } & Desorption & $25.0 \mathrm{psi}$ \\
\hline Transfer line & Water-resistant & Hydroguard \\
\end{tabular}


Table 2: Mass spectrometer settings

\begin{tabular}{|c|c|}
\hline MS parameters & Settings \\
\hline Ionization mode & Electron Ionization (EI) \\
\hline Solvent delay & $6 \mathrm{~min}$ \\
\hline Chromatographic time & $47-33 \mathrm{~min}$ \\
\hline Total Ions Chromatogram (TIC) & 10 channels with 3 ions \\
\hline Single ions recording (SIR) & $0.02 \mathrm{~s}$ \\
\hline Dwell Time & $0.02 \mathrm{~s}$ \\
\hline Inter-Channel Delay & 1 \\
\hline Repeats & 1 \\
\hline Span &
\end{tabular}


Table 3: SIR settings for the studied VOCs

\begin{tabular}{|c|c|c|c|c|}
\hline Compound & $\begin{array}{c}\text { Retention time } \\
\text { (Rt, in min) }\end{array}$ & Trace & $\begin{array}{c}\text { SIR window } \\
\text { (Rt, in min) }\end{array}$ & $\begin{array}{c}\text { Monitored ions } \\
\text { Quantification } \\
\text { ions }\end{array}$ \\
\hline Dichloromethane & 7.24 & SIR1 & 6.00 to 8.50 & $49 ; \underline{84} ; 86$ \\
\hline Chloroform & 10.26 & SIR2 & 8.50 to 11.0 & $49 ; \underline{83 ; 85}$ \\
\hline Benzene & 11.71 & SIR3 & 10.90 to 13.00 & $50 ; 77 ; \underline{78}$ \\
\hline Trichloroethylene & 13.35 & SIR4 & 12.50 to 15.00 & $95 ; 130 ; 132$ \\
\hline Toluene-D8 & 16.80 & SIR5 & 15 to 18.50 & $70 ; 98 ; 100$ \\
\hline Toluene & 17.07 & SIR6 & 15.60 to 19.00 & $65 ; 91 ; 92$ \\
\hline Tetrachloroethylene & 19.92 & SIR7 & 18.50 to 22.50 & $129 ; 164 ; \underline{166}$ \\
\hline Ethylbenzene & 25.03 & SIR8 & 22.50 to 28.00 & $\underline{91 ; 105 ; 106}$ \\
\hline m-xylene & 26.00 & SIR8 & 22.50 to 28.00 & $\underline{91 ; 105 ; 106}$ \\
\hline p-xylene & 26.17 & SIR8 & 22.50 to 28.00 & $\underline{91 ; 105 ; 106}$ \\
\hline Styrene & 28.77 & SIR9 & 28.00 to 32.00 & $91 ; 103 ; 104$ \\
\hline o-xylene & 29.00 & SIR10 & 28.10 to 32.00 & $\underline{91 ; 105 ; 106}$ \\
\hline
\end{tabular}


Table 4: Precision for each unmetabolized VOC obtained from urine samples spiked at three concentration levels $(0.008,2$ and $20 \mu \mathrm{g} / \mathrm{L})$

\begin{tabular}{|l|c|c|c|c|c|c|}
\hline \multirow{2}{*}{ Compounds } & \multicolumn{3}{|c|}{ Within-day precision $(\mathrm{CV}$ in \%) } & \multicolumn{3}{c|}{ Between-day precision $(\mathrm{CV}$ in \%) } \\
\cline { 2 - 7 } & $0.08 \mu \mathrm{g} / \mathrm{L}$ & $2 \mu \mathrm{g} / \mathrm{L}$ & $20 \mu \mathrm{g} / \mathrm{L}$ & $0.08 \mu \mathrm{g} / \mathrm{L}$ & $2 \mu \mathrm{g} / \mathrm{L}$ & $20 \mu \mathrm{g} / \mathrm{L}$ \\
\hline Dichloromethane & 5.5 & 1.3 & 2.1 & 4.3 & 3.2 & 6.7 \\
\hline Chloroform & 3.6 & 3.2 & 3.3 & 3.6 & 3.6 & 2.4 \\
\hline Benzene & 4.0 & 1.5 & 3.1 & 4.2 & 3.7 & 7.5 \\
\hline Trichloroethylene & 2.2 & 1.9 & 3.4 & 3.5 & 3.8 & 6.8 \\
\hline Toluene & 2.4 & 2.1 & 3.8 & 3.9 & 6.3 & 5.7 \\
\hline Tetrachloroethylene & 3.4 & 0.9 & 3.6 & 2.7 & 3.9 & 6.1 \\
\hline Ethylbenzene & 2.1 & 1.4 & 3.7 & 7.1 & 6.5 & 7.0 \\
\hline m-xylene & 2.4 & 1.0 & 4.0 & 3.6 & 6.1 & 8.8 \\
\hline p-xylene & 3.4 & 1.5 & 4.5 & 3.8 & 6.2 & 5.6 \\
\hline Styrene & 3.4 & 1.2 & 2.7 & 8.5 & 4.5 & 9.4 \\
\hline o-xylene & 3.2 & 1.4 & 2.1 & 5.5 & 6.2 & 8.7 \\
\hline
\end{tabular}


Table 5: Pre- and post-shift urinary levels (in $\mu \mathrm{g} / \mathrm{L}$ ) of the VOCs studied in exposed non-smoking workers at the three plants (*: statistical difference between post-shift and pre-shift concentrations, p-value<0.05)

\begin{tabular}{|c|c|c|c|c|c|c|c|}
\hline Plant & $\begin{array}{l}\text { Time of } \\
\text { urine } \\
\text { collection }\end{array}$ & VOC & $\begin{array}{c}\text { Number of } \\
\text { exposed } \\
\text { workers }\end{array}$ & $\begin{array}{c}\text { Number of } \\
\text { samples } \\
\text { collected }\end{array}$ & Median & Range & $\begin{array}{c}\text { Number } \\
\text { of values } \\
<\text { LOQ }\end{array}$ \\
\hline \multirow{10}{*}{$\begin{array}{c}\text { Paints, } \\
\text { varnish } \\
\text { and resins }\end{array}$} & \multirow{5}{*}{ Pre-shift } & Chloroform & 18 & 55 & 0.01 & $<$ LOQ-2.05 & 24 \\
\hline & & Toluene & 18 & 55 & 0.16 & $0.03-0.63$ & 0 \\
\hline & & Ethylbenzene & 18 & 55 & 0.05 & $0.01-0.18$ & 0 \\
\hline & & Styrene & 18 & 55 & $<\mathrm{LOQ}$ & $<$ LOQ-0.12 & 52 \\
\hline & & Xylenes & 18 & 55 & 0.22 & $0.02-0.80$ & 0 \\
\hline & \multirow{5}{*}{ Post-shift } & Chloroform & 18 & 44 & 0.01 & $<$ LOQ-0.93 & 18 \\
\hline & & Toluene & 18 & 44 & 0.14 & $0.01-0.35$ & 0 \\
\hline & & Ethylbenzene* & 18 & 44 & 0.06 & $0.02-0.51$ & 0 \\
\hline & & Styrene & 18 & 44 & $<\mathrm{LOQ}$ & $<$ LOQ-0.24 & 36 \\
\hline & & Xylenes* & 18 & 44 & 0.26 & $0.07-2.29$ & 0 \\
\hline \multirow{4}{*}{ Synthesis } & \multirow{2}{*}{ Pre-shift } & Dichloromethane & 19 & 58 & 0.05 & $<$ LOQ-8.22 & 5 \\
\hline & & Toluene & 19 & 30 & 0.31 & $0.15-1.75$ & 0 \\
\hline & \multirow{2}{*}{ Post-shift } & Dichloromethane* & 19 & 61 & 0.28 & $0.01-22.66$ & 0 \\
\hline & & Toluene* & 19 & 23 & 0.54 & $0.19-8.15$ & 0 \\
\hline \multirow{8}{*}{$\begin{array}{c}\text { Oil } \\
\text { refinery }\end{array}$} & \multirow{4}{*}{ Pre-shift } & Benzene & 23 & 62 & 0.07 & $0.02-1.92$ & 0 \\
\hline & & Toluene & 23 & 62 & 0.13 & $<$ LOQ-0.69 & 12 \\
\hline & & Ethylbenzene & 23 & 62 & 0.08 & $0.06-0.23$ & 0 \\
\hline & & Xylenes & 23 & 62 & 0.26 & $0.17-0.44$ & 0 \\
\hline & \multirow{4}{*}{ Post-shift } & Benzene* & 23 & 62 & 0.23 & $0.03-2.74$ & 0 \\
\hline & & Toluene* & 23 & 62 & 0.18 & $<$ LOQ-1.23 & 3 \\
\hline & & Ethylbenzene* & 23 & 62 & 0.10 & $0.07-0.21$ & 0 \\
\hline & & Xylenes* & 23 & 62 & 0.28 & $0.19-0.50$ & 0 \\
\hline
\end{tabular}

